Purdue University Purdue e-Pubs

ASEE IL-IN Section Conference

\title{
Using a Lightboard to Enhance and Retrofit an Existing Course
}

Nicholas S. Rosasco

Valparaiso University

Follow this and additional works at: https://docs.lib.purdue.edu/aseeil-insectionconference

Rosasco, Nicholas S., "Using a Lightboard to Enhance and Retrofit an Existing Course" (2018). ASEE IL-IN Section Conference. 6. https://docs.lib.purdue.edu/aseeil-insectionconference/2018/innov/6

This document has been made available through Purdue e-Pubs, a service of the Purdue University Libraries. Please contact epubs@purdue.edu for additional information. 


\title{
Using a Lightboard to Enhance and Retrofit an Existing Course
}

\author{
Nicholas S. Rosasco \\ Department of Computing and Information Sciences, Valparaiso University
}

\begin{abstract}
IT 642 is a graduate information technology course that addresses a mix of technical and conceptual topics that has been delivered in both in-person and on-line formats. After several semesters of the course being offered in both on-line and in-person formats, the lack of human connection between instructor and students became a concern with the online versions. The need to bridge this gap became an opportunity to use Birdwell and Peshkin's Lightboard design for video teaching. The experiences of the staff and faculty involved confirms the low barrier to entry they describe for using this technology and also demonstrate utility for the system beyond the need to present equation illustrations and scientific problems that were the original inspiration for the tool.

This paper also includes some information regarding variations in configuration from the original Northwestern University design, some inspired by local circumstances and some derived from visits to similar tools setup at neighboring institutions, which may be of some interest to other adopters. Additionally, contextual information and general circumstances that led to a successful adoption are presented.
\end{abstract}

\section{Introduction and motivation}

IT 642, Information Assurance, is a graduate information technology course offered by Valparaiso University that addresses a mix of technical and abstract concepts in cyber security. The University is a regional master's university of approximately 4,500 students and is relatively new to supporting online programs. The first several editions of the course relied heavily on written material and included more than six writing assignments intended to be critical thinking exercises. This was in addition to the approximately twenty thousand words of lecture summaries originally created from the in-person version of the class.

After running the class over several semesters, the primary instructor opted to participate in a campus workshop on online teaching and used this course as a focus. This workshop was created by Valparaiso University to facilitate the transition of classes to online formats, and was intended to provide information on both technologies and best practices. The workshop strongly recommended the use of video, in part to better connect with students. At the time, the options available on campus for video-based teaching did not provide the quality, depth of connection, or presence that was desired (as shown in Figure 1). A separate initiative from the College of Engineering led to an opportunity to try a variation on the Lightboard design of Birdwell and Peshkin [1,8] after one was installed during the summer of 2016. This system provides an easy to use way to record video with a see-through writing surface that can be used like a conventional whiteboard. 
Even though IT 642 does not have the mathematical or diagram driven-example questions for which Lightboard videos have often been user, it was adopted for the course. The results from this test largely confirms the low barrier to entry for this technology and also demonstrate its utility in areas beyond those original strengths - beyond those originally suggested for the system. These needs could not be met effectively with a web camera, document camera, or screenshots, the other available options. Additionally, the general circumstances for this created a situation that is distinct from most other, earlier Lightboard setups, which have often been built as a student experiment or with greater staff and budget availability $[2,3,9,10]$.
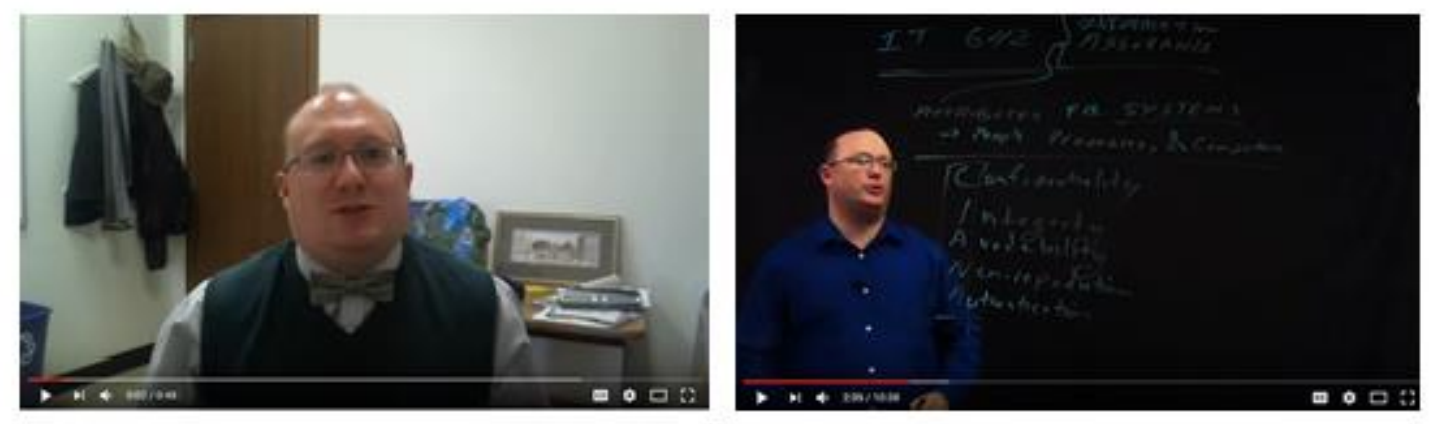

Figure 1: Side by Side Comparison - Standard web camera versus a Lightboard

The timetable for the build of the Valparaiso implementation of the Lightboard permitted the use of the system for the summer 2016 academic term and the third repetition of IT 642 with the same instructor. This summer section was predominantly composed of online students, accessing the class asynchronously. The online students typically take one or two classes per term to balance schoolwork with work and family commitments. This made ensuring a quality experience particularly important, as this course was normally taken early in the degree program, where retention is an institutional concern. The existing workload for the course had been well received and generally seen was described as challenging but achievable. These considerations meant that adding significantly to the student time commitment was not desirable, making the primary goal for the video material to provide some variety and punctuation versus the large amount of reading and writing required.

There was a secondary goal of trying to close the apparent gaps that resulted from minor but noticeable disconnects on assignments. In-person students tended to have a greater awareness of the emphasis and intent of some of the coursework, as they had the opportunity of freeform interaction with the instructor when the assignments were presented. This created a potentially unfair situation between the students in the two versions. This was particularly problematic when sections were run concurrently and grading needed to be consistent. The video material would, it was hoped, become a mechanism for smoothing out those inconsistencies by providing a higher density form of communication beyond just written directions, while still making few modifications to what had proved to be a successful course.

\section{The Lightboard tool}

A Lightboard system is consists of a camera, separate microphone, and a pane of transparent glass that has been mounted vertically, in a frame similar to a movable chalkboard. The 
instructor stands and writes on one side of the glass, the camera sits on the opposite side, and the resulting image is horizontally flipped to create a finished product. Additional post production is possible but not usually required. This creates a very easy, teaching-centered environment (shown in Figure 2) that mimics the conventional chalkboard or whiteboard arrangement and allows online viewers to maintain eye-contact with the instructor. This environment, generally, has been found effective for the original uses of this class of tool - including recording example problems and creating video for flipped of classrooms $[1,6,8]$.

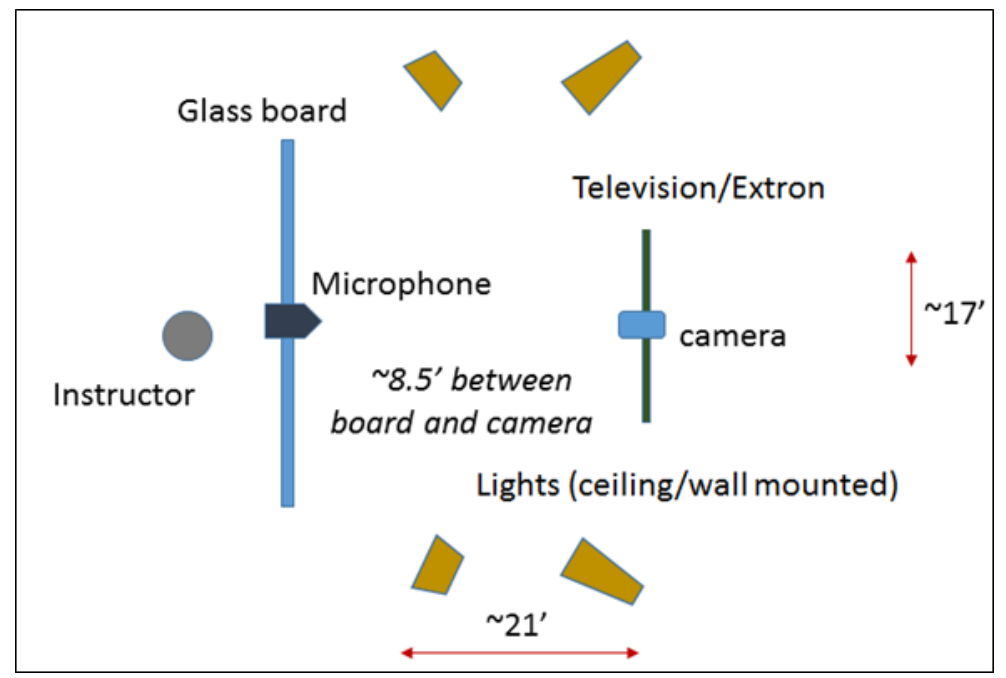

Figure 2: Simplified Layout of the Lightboard Studio, as Currently Configured

\section{Setup of the Valparaiso University version of the tool}

The Valparaiso University IT office also simplified the Northwestern design by using simple black fabric behind the instructor and board, instead of a photographic backdrop. Costs were further contained by the use of an available soundproof TV studio room. At Valparaiso, this lightly used facility also supports the Meteorology program, the student-run campus TV station, and the Digital Media and Communications program. The room was already equipped for use as a studio, with two spotlights plus several large lights, mounted near the top of the wall or from the ceiling. As noted in Figure 2 the studio space is approximately 21 ' by 17 '.

The Valparaiso University Lightboard variant employs tempered safety glass to mitigate any issues that might result from the board mount failing or toppling during movement. The existing lighting in the room was deemed sufficient during initial trials, allowing the elimination of the side LEDs incorporated into the original Northwestern implementation and saving additional lighting expense.

Other elements of the system include:

- Luxor FP4000 Adjustable Height LCD TV Stand and Mount with Accessory Shelf and Camera Mount,

- Canon 32GB VIXIA HF G20 Full HD Camcorder,

- Bower 3-Piece 58mm Filter Kit,

- Vidpro XM-88 Shotgun Microphone Kit, 
- Weymic 35 Universal Microphone Suspension Boom Scissor Arm Stand with Holder for Broadcast Studio Microphone,

- Extron SMP 351 H.264 Streaming Media Processor (the primary recording and control unit), plus a

- $\quad$ Samsung H5003 Series 40" Class Full HD LED TV

While several considerations, including the reuse of the existing room and lighting arrangement, make it difficult to compute 'from scratch' costs, the overall budget for the project was less than $\$ 10,000$ U.S., which included some incremental upgrades and replacements during initial use.

\section{Observations from use}

Several aspects of Valparaiso's plan for rolling out this tool contributed to the success of this early use. The use of a student aide as an operator, particularly for the initial sessions, was a significant assist. The extra set of hands made starting and stopping recording much simpler and more fluid. This was particularly true as the iterative approach used to system deployment meant initial use was not as straightforward as using the system in its later configuration. This approach did allow for easier fine tuning, however, and ensured ongoing staff involvement and engagement. Having immediate feedback on the video and audio quality, as well as not having to recall all startup and shutdown steps also contributed to overall ease of use for faculty. Further, this was an easy way to help ensure the faculty member would look at the camera (and remind them if necessary).

Student feedback from the course where the Lightboard was employed included a note that color contrast, between both the background and the colors of the markers, could be better. It was also apparent that the size of the board (and the need to clean it) could occasionally disrupt the flow of presentation. While these are minor issues, they are the only issues or criticisms directly related to the Lightboard that have been seen in student course assessments or feedback. The overall feedback also indicates that impression of the course tracks with the non-video editions.

A second delivery of the course in summer 2017, with no significant modifications from the prior course, provided the chance to collect additional student evaluation-based feedback. This repetition confirmed the generally positive impression. Multiple comments included praise for the inclusion of the videos, including a request to "continue to include the video lectures to supplement the written lecture notes." There was also a comment that "incorporating video lectures with the written notes is a plus for students enrolled in the online class, and that the technology "made it as though this online course was an in person course." Interestingly, the use of 10 to 15 minute length videos (a recommendation of the workshop) was apparently not enough for one student, who stated that "I actually would have liked longer lectures."

Homework assignments and projects for the course also showed overall improvement. While difficult to measure, there was an overall impression of improved understanding of and identification of key concepts and points of emphasis. This is of some particular interest, as the class is largely built around consideration of abstract concepts and systems-focused decision making and goals, which is a departure from the original uses of the Lightboard for mathematical and scientific examples [1]. This use is close to but also distinct from the procedural and administrative questions that have been presented using the tool [4]. 
For the contrast issue, some tuning to the contrast settings on the camera is expected to help. The pauses necessary to clean the board itself have proved useful, despite the interruption to the flow of presentation they create. Typically, the board is "full" after about five to ten minutes of discussion, which reinforces the recommended time for a given presentation. [Best Practices section - 8,10] This punctuation encourages the instructor to select key items for emphasis, rather than simply redelivering a complete lecture. Experience and some experimentation led to a minor but handy discovery that a set of microfiber cloths was a useful addition to the setup, as it made for easier cleaning than traditional paper towels (which had required frequent resupply).

More generally from the faculty point of view, integrating the tool into the course on the third iteration helped significantly. There had been opportunities for reflection and discovery, for fine tuning of assignments, and a complete course to be developed and considered. The addition of the videos and testing a new tool was significantly easier on the teacher when it was possible and acceptable to fall back to the existing materials should, for example, a particular week's filming encounter any technical issues. Having the faculty member able to book shorter blocks so that only two or three short videos were recorded in one session also meant the resulting videos were usually somewhat more consistent in focus and each presentation was delivered with a higher energy level.

\section{Conclusions and next steps}

Further evolution of the Valparaiso University Lightboard suite may include incorporation of the One Button Studio recording platform [7], to further ease and simplify solo operation of the system. Immediate plans include advertising the facility more widely around campus, and providing information to new hires alongside the other teaching and instructional technologies available on campus. There has been discussion of using the system to link to a remote classroom, for synchronous distance education, to leverage the multiple sites available to the University, which has an offsite facility in a nearby metro area particularly well placed for attracting currently employed students as well as several study abroad sites.

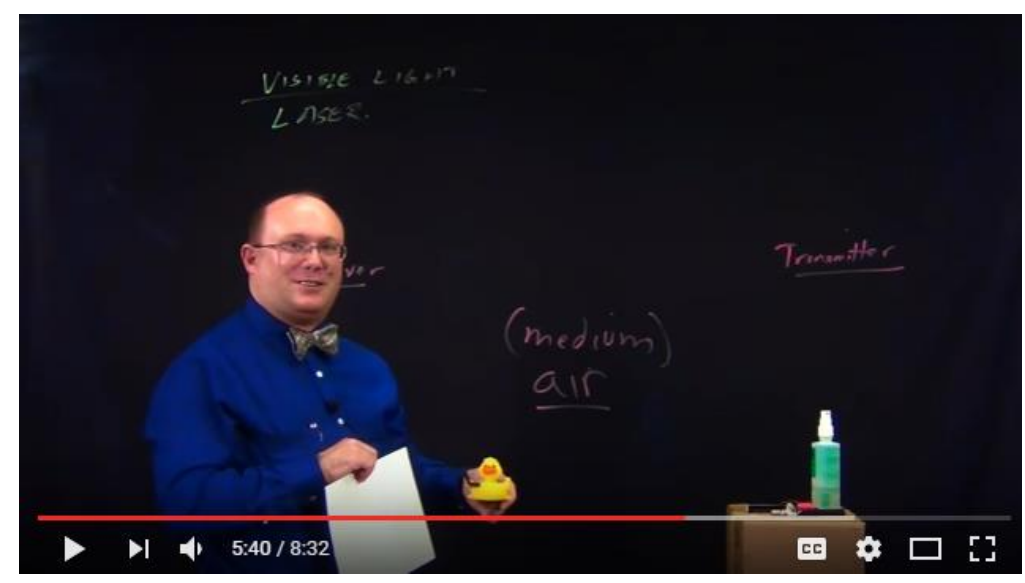

Figure 3: The Lightboard used as a tool for 'floating' labels over physical objects 
In the asynchronous mode, this tool may also become a tool for providing a richer catalog for summer instruction, as it can free faculty from the need to be available on campus for the duration of the full summer term. Eligible students will also benefit from being able to attend online format courses of higher quality, as a library of possible offerings is created. It is expected that preparatory or remedial offerings may also benefit from the addition of video presentations, as recordings can be repeated and enhanced based on student's reactions and assessment results.

Later use with other, similar courses has demonstrated (Figure 3) that it presents unique opportunities to annotate the environment. Particularly when used in conjunction with physical components, this capability could prove to be potent asset for use in the traditional sciences and the lab-heavy disciplines

Additionally, as students become familiar with the tool's use, there has also been more immediate feedback. For a later class that used the Lightboard in a similar way, some students on their second experience with the system started using the commenting tool built into Youtube, which was used to host the videos. This additional feedback channel, integrated with the delivery system, may prove to be an especially useful way for students to make comments and pose follow-up questions (see example in the screen capture shown in Figure 4). It has the further advantage of being another way to help replicate some aspects of the in-person "feel" for on-line only students. Shaping the experience of the distance student so as to provide more of that authenticity and atmosphere has been an ongoing consideration, both at Valparaiso and generally [10].

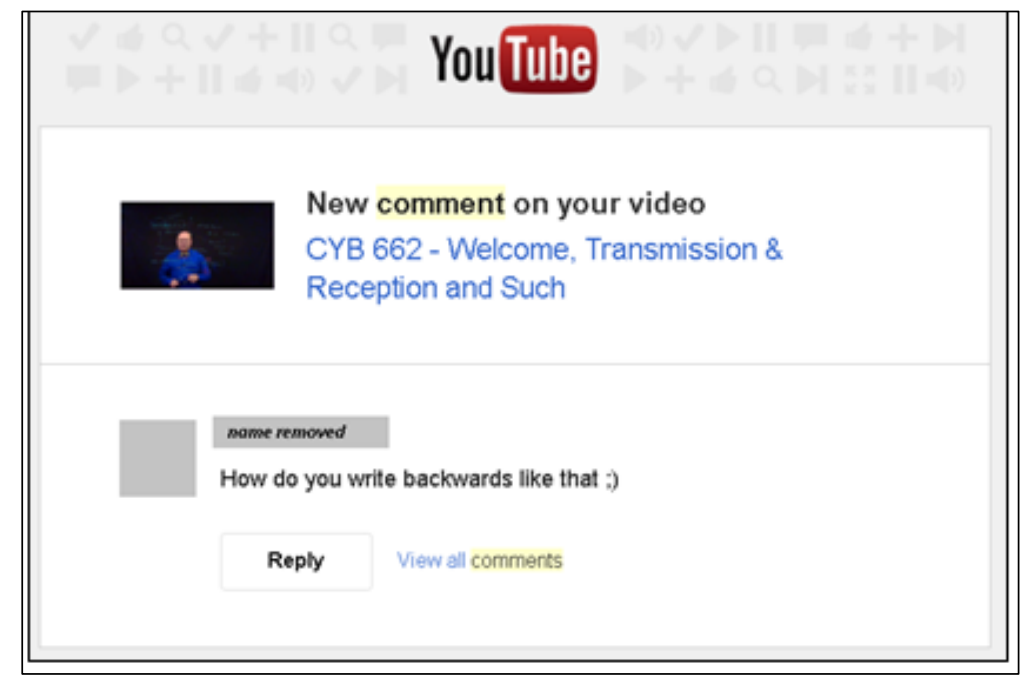

Figure 4: Example Student Comment

Finally, it is reasonable to infer from this experience that this tool delivers the promised utility at a cost well within reach of smaller and midsize institutions, in such a way as to be extremely user friendly and supportable for both faculty and staff. 


\section{Acknowledgements}

Major thanks are due to Kevin Steele from the Valparaiso Information Technology office and Continuous Improvement group for his work in building the system and his help assembling the information for this paper. Similar appreciation goes to Erik Kispert and the College of Engineering generally for their support during the investigation of the tool. Recognition is also due to the various student staffers for their help in operating the system - and being patient with faculty during the process of using it! Acknowledgement is also due to Dan White and Ruth Wertz, faculty in the College of Engineering, who advocated for the acquisition and installation of the system.

The author and the Valparaiso University team are also deeply grateful to the faculty and team at Northwestern for openly sharing the idea and design with the wider community, and the Lightboard deploy and support group at the University of Notre Dame, who were kind enough to make time to demonstrate their implementation and share knowledge.

\section{References}

1 Birdwell, J., and Michael Peshkin. "Capturing Technical Lectures on Lightboard.” In 2015 ASEE Annual Conference and Exposition Proceedings, 26.325.1-26.325.9,ASEE Conferences, 2015. doi:10.18260/p.23664

2 “DIY Lightboard." http://www.instructables.com/id/DIY-Lightboard/ , 2017, (Accessed January 2017).

3 EDUCAUSE. "7 Things You Should Know About Lightboard." http://net.educause.edu/ir/library/pdf/ELI7111.pdf, 2017, (Accessed January 29 2017).

4 Freeman, Richard, Ken Gentry, and Jenna Goldberg. "Changing the Advising Model.” In 2016 ASEE Annual Conference \& Exposition Proceedings, ASEE Conferences, 2016. doi:10.18260/p.26478

5 Lynch, E. D. W. 'Ingenious Dry-Erase Glass 'Lightboard' for Video Lectures Allows Presenter to Face Camera While Writing." http://laughingsquid.com/ingenious-dry-erase-glass-lightboard-for-video-lecturesallows-presenter-to-face-camera-while-writing/, 2013 (Accessed February 2017).

6 Meyer, Leila. "5 Lecture Capture Hacks for More Engaging Videos -- Campus Technology." https://campustechnology.com/articles/2015/04/08/5-lecture-capture-hacks-for-more-engaging-videos.aspx, 2017, (Accessed January 2017).

7 Oberdick, Jamie. "Teaching and Learning with Technology | Lightboard Integrates with One Button Studio to Enable More Engaging Teaching Videos.” http://tlt.psu.edu/2015/03/11/lightboard-integrates-with-onebutton-studio-to-enable-more-engaging-teaching-videos/, 2015, (Accessed February 2017).

8 Peshkin, Michael. 2017. "How to Build a Lightboard." http://lightboard.info/, 2017, (Accessed February 2017).

9 Stanford Online. "The Light Board.” http://online.stanford.edu/news/2014/12/18/light-board, 2017, (Accessed January 29 2017).

10 Young, Jeffrey R. "How to Prepare Professors Who Thought They'd Never Teach Online." Chronicle of Higher Education. http://chronicle.com/article/How-to-Prepare-Professors-Who/236873, 2016, (Accessed February 2017). 